El texto plantea algunas reflexiones sobre aspectos que reconfiguran la cultura y el ejercicio de los derechos culturales en el marco de la pospandemia. Se abren algunas líneas de investigación sobre lo que implica pensar, desde diversos órdenes de la cultura, lo que se ha denominado como "nueva normalidad". Se propone para ello partir de la convivenciabilidad como una forma de crear y producir cultura.

Palabras clave: pospandemia; CovID-19; derechos culturales; prácticas culturales; convivenciabilidad

\title{
Cultura y ejercicio de los derechos culturales en la pospandemia:
} notas desde la convivenciabilidad

Cristina Amescua Chávez cristina.amescua@crim.unam.mx

Juan Carlos Domínguez Domingo jcdominguezdomingo@gmail.com

\section{Introducción}

En un contexto como el que hemos vivido durante los últimos meses y como el que enfrentaremos ahora con la construcción de la llamada nueva normalidad, nos preguntamos de qué manera se está reconfigurando la cultura y cómo podrá hacerse efectivo el ejercicio de los derechos culturales de las comunidades y grupos sociales a lo largo y ancho del planeta, particularmente en México, nuestro país.

Más allá de las incontables definiciones del concepto cultura, vale simplemente aclarar que aquí la entenderemos como esa forma colectiva de crear significados que orientan nuestra percepción del mundo

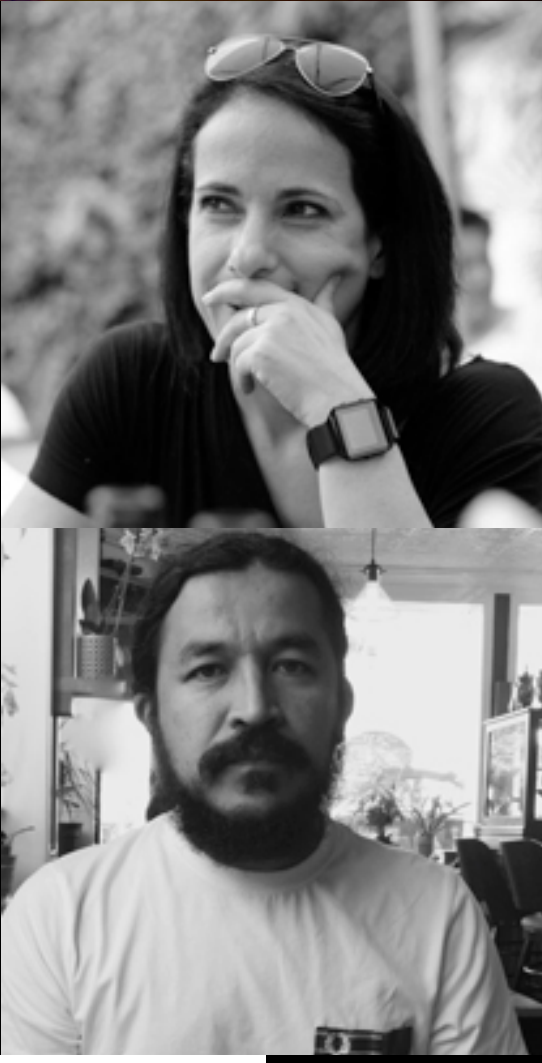


y nos construyen como seres sociales que habitamos, entendemos y accionamos en grupos sociales específicos - pero diversos- en contextos particulares - pero cambiantesAsí, la cultura está lejos de constituir un andamiaje inamovible, por el contrario, está siempre sujeta a negociaciones y transformaciones.

Vale la pena recordar que la cultura y sus prácticas se sustentan en actividades colectivas y de reciprocidad que son fundamentales para darle sentido y continuidad a la vida y a la reproducción social. Esta dimensión colectiva, que empieza desde el núcleo familiar más íntimo, se extiende hasta abarcar los espacios públicos, que más allá de ser arena para la expresión de las culturas, son los espacios donde se crea y recrea, en los que se transforma y se reconfigura de acuerdo con las características y las necesidades de cada contexto socioeconómico, político, histórico y social. En este sentido, ¿cómo puede una nación como México - que se reconoce como pluricultural, diversa y plurilingüe- asegurar el respeto y las condiciones de reproducción de la diversidad cultural de los grupos que la conforman si ahora se nos pide evitar, $u$

ca

El confinamiento ha producido

efectos inesperados en la transmisión

de conocimientos tradicionales

que ya no se estaban reproduciendo

de padres a hijos." ocupar parcialmente y con "sana distancia", ese espacio público en el que se produce y reproduce la cultura, y que no reconoce necesariamente en la virtualidad tecnológica un espacio que sustituya el lugar en el que transcurre la esencia de la vida social?

La antropóloga Lourdes Arizpe, en su más reciente libro, propone el término de convivenciabilidad como un concepto diferente de sociabilidad humana. Nos dice que este concepto le vino a la mente al escuchar una canción mexica datada en 1580. La melodía muestra cómo las personas adquieren su ser a través de las interacciones sociales. La canción dice “ ¡Vengo, aparezco! ¡Amigos, vengo como creado por una canción! ¡He llegado a crear una compañía de amigos!”. En ello se aprecia, nos dice Lourdes Arizpe, que en varias lenguas mesoamericanas las palabras asociadas al ser presentan connotaciones de conexión con los demás. La convivenciabilidad propone superar el "sí mismo en sentido occidental, [pues] uno es todos los demás” (Arizpe, 2019, p. 276). ¿Pero cómo entonces podemos ser todos los demás si no podemos mirarnos a los ojos, tocarnos, olernos, sentirnos?

Durante los más de noventa días transcurridos desde la expansión de la pandemia en el país, periodo en el que se nos conminó a dejar de interactuar en el espacio público, la forma en la que esta convivenciabilidad se ha visto trastocada es diversa. Si bien cada pueblo, comunidad y grupo social ha enfrentado y se ha adaptado a estas condiciones de confinamiento, hay que reconocer que en muchos casos la vida comunitaria basada en ritos, fiestas, celebraciones y prácticas colectivas se ha visto alterada, lo cual resulta en modificaciones más o menos profundas $-\mathrm{y}$, con seguridad, desigualmente duraderas - del tejido social y de los elementos que le dan cohesión y equilibrio. Esto sin duda conlleva a desarrollar diversas líneas de reflexión, aquí proponemos algunas.

\section{La cultura en la pospandemia}

La pandemia de covid-19 y las medidas de mitigación como el confinamiento y el distanciamiento social están produciendo efectos paradójicos a nivel social y cultural. Aquí apuntamos solo algunas de estas paradojas, subrayando que la mayoría se insertan en contextos socioeconómicos con profundas desigualdades previas a la pandemia que, sin duda, se verán agravadas en los tiempos por venir. 


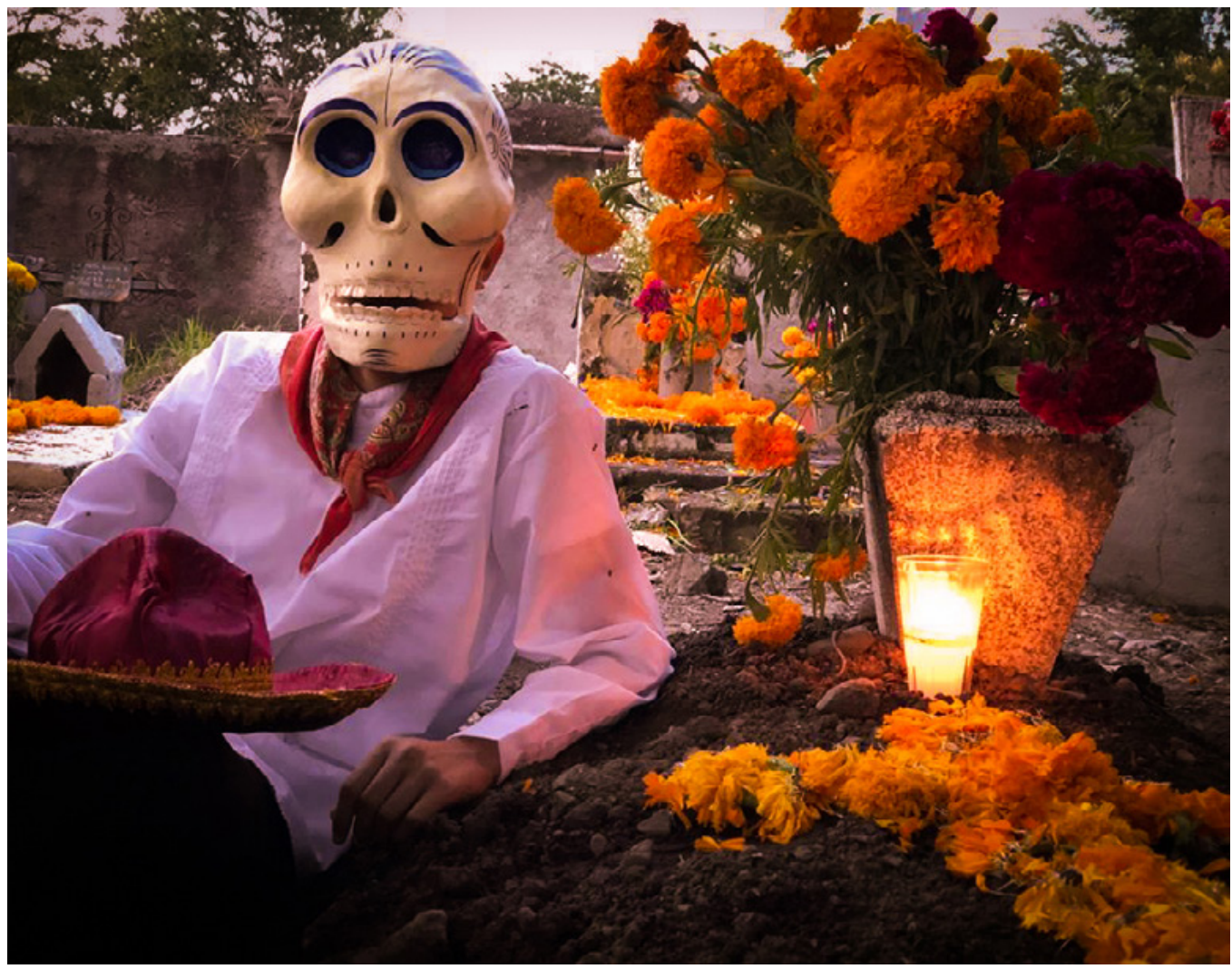

1. Las escalas de la reproducción cultural. Como apuntamos arriba, el distanciamiento social ha reducido o anulado - en algunos casos, pues se sabe bien que en muchas comunidades, sobre todo las rurales, la vida ha continuado prácticamente inalterada - el uso del espacio público como un lugar para la construcción y reproducción de la cultura, esto sin duda alguna tendrá efectos importantes en un futuro. Sin embargo, otro de los ámbitos fundamentales de la reproducción cultural se ha visto favorecido por estas medidas, nos referimos aquí al ámbito familiar. En efecto, y como ha sido documentando por la Unesco y otras organizaciones, en las últimas semanas el confinamiento ha producido efectos inesperados en la transmisión de conocimientos tradicionales que ya no se estaban pasando de padres a hijos. Nos referimos aquí, por ejemplo, a los saberes culinarios, a los conocimientos artesanales, a la historia oral o a la música. Así, uno de los posibles efectos de esta pandemia puede ser la revitalización de muchos conocimientos y prácticas que estaban en vías de desaparición por la profunda afectación que la acelerada vida moderna produce en sus sistemas de transmisión. Por supuesto, esto solamente puede darse en ámbitos familiares y domésticos que no estén permeados en su totalidad por carencias fundamentales $\mathrm{y}$ por formas de sociabilidad violentas, discriminatorias y excluyentes.

2. Las formas reconocidas y validadas de sociabilidad y contacto interpersonal. La amplia difusión de los mecanismos de reproducción del virus, y por lo tanto, de las formas de contenerlo, pueden estar provocando, sobre todo entre los más jóvenes, la implantación de nuevas ideas - de un nuevo marco cultural — sobre la pureza y el peligro, para ponerlo en términos de Mary Douglas (1973). Así, al parecer, lo que es indispensable para el mantenimiento actual de nuestra salud, a saber la "sana distancia", puede convertirse en la base para dejar atrás el contacto físico cercano, el apapacho, que es una parte central de nuestra sociabilización, por lo menos en México. 


\section{ca}

Los nuevos escenarios de la pandemia

mantienen detenidas las prácticas culturales

de muchos pueblos y comunidades

para los cuales la convivenciabilidad

es fundamental." apenas algún pronunciamiento institucional que haga notar que los nuevos escenarios de la pandemia mantienen detenidas las prácticas culturales de muchos pueblos y comunidades para los cuales la convivenciabilidad es fundamental. Además, valdría la pena indagar las posibilidades de existencia y las formas que adquiere esta con-

vivenciabilidad digital exacerbada. ¿Sustituye a la convivenciabilidad presencial? ¿Puede complementarla? ¿Cómo lo haría? ¿Qué tanto estas son nuevas formas de "estar y ser juntos" que llegaron para quedarse?

A lo largo de las semanas de la pandemia, a los temas de salud se han sumado los informes diarios del Gobierno de México con temáticas de empleo, economía y bienestar, pero hasta ahora la cultura ha estado ausente, sobre todo para abordar el tema desde una visión más amplia que la del acceso. ¿No debería ser considerado el ejercicio de los derechos culturales expresado en la (re)producción cultural comunitaria dentro de los planes para retomar los escenarios de la normalidad? Así como se habla de abrir hoteles, fábricas, centros comerciales, etcétera, ¿no sería necesario plantear de qué forma estas prácticas deben darse sin poner en riesgo la salud de las poblaciones que las practican? Creemos que sí, que hay muchos temas pendientes para todos los actores involucrados: para el Estado en primer lugar, pero también para los científicos sociales, para los gestores y promotores culturales, para las organizaciones sociales y para la gente en las comunidades que durante siglos se han encargado de asegurar la reproducción de sus prácticas culturales más queridas y significativas.

\section{Referencias}

Arizpe, L. (2019). Cultura, transacciones internacionales y el Antropoceno. Centro Regional de Investigaciones Multidisciplinarias UnAM; Miguel Ángel Porrúa.

Douglas, M. (1973). Pureza y peligro: un análisis de los conceptos de contaminación y tabú. Siglo XXI.

Instituto Nacional de Estadística y Geografía. (2020). En México hay 80.6 millones de usuarios de internet y 86.5 millones de usuarios de teléfonos celulares: ENDUTIH 2019. Boletín de prensa. https://www.inegi.org.mx/contenidos/saladeprensa/ boletines/2020/OtrTemEcon/ENDUTIH_2019.pdf

Unesco. (2020). COVID-19 Respuesta. https://es.unesco.org/covid19

Para citar esta nota: Amescua, C. y Domínguez, J. C. (3 de julio de 2020). Cultura y ejercicio de los derechos culturales en la pospandemia: notas desde la convivenciabilidad. Notas de coyuntura del CRIM No. 41, México, CRIM-UnAm, 5 pp. 